Citation: Pannell, D.J., Alston, J.M., Jeffrey, S., Buckley, Y.M., Vesk, P., Rhode, J.R., McDonald-Madden, E., Nally, S., Gouche, G. and Thamo, T. (2018). Policy-oriented environmental research: What is it worth? Environmental Science and Policy 86, 6471.

\title{
Policy-oriented environmental research: What is it worth?
}

David J. Pannell ${ }^{1 *}$, Julian Alston², Scott Jeffrey ${ }^{3}$, Yvonne M. Buckley ${ }^{4}$, Peter Vesk ${ }^{5}$, Jonathan R. Rhodes ${ }^{6}$, Eve McDonald-Madden ${ }^{6}$, Simon Nally ${ }^{7}$, Garry Goucher ${ }^{8}$ and Tas Thamo $^{1}$

${ }^{1}$ University of Western Australia, Perth, Australia, ${ }^{2}$ University of California, Davis, ${ }^{3}$ University of Alberta, Canada, ${ }^{4}$ School of Natural Sciences, Zoology, Trinity College Dublin, Dublin 2, Ireland, ${ }^{5}$ University of Melbourne, Australia, ${ }^{6}$ University of Queensland, School of Earth and Environmental Sciences, Brisbane, Australia, ${ }^{7}$ Department of the Environment and Energy, Canberra, Australia, ${ }^{8}$ Garry Goucher and Associates, Australia

*Corresponding author. E-mail: david.pannell@uwa.edu.au

\section{Highlights}

- Evidence about the benefits to society from research is increasingly demanded

- Economic models to evaluate the benefits of research exist but have not been applied to environmental research

- We outline a framework for estimating the benefits of policy-oriented environmental research

- Key elements include defining the counterfactual, time lags and valuing the benefits 
- Applications to environmental research are especially challenging because the research users are policymakers

- There are many elements in the chain from research to environmental outcomes

\section{Abstract}

Environmental and conservation scientists are increasingly being asked to justify their work in terms of benefits to society. This article describes economic theory for conceptualizing the benefits from environmental research, and provides a framework for estimating those benefits. In particular we discuss the evaluation of environmental science that is intended to benefit society through informing policy decisions. The chain between environmental research and its benefits through policy change includes at least four links: the research itself, policy change, behavior change and environmental change. Each of these four stages presents challenges and entails time lags. If any link fails, the chain breaks. The standard economic model of supply and demand, which is used to quantify benefits from research into market goods, can be adapted for application to environmental goods. Improved conceptualization and measurement of benefits from environmental research would assist environmental scientists to: (1) select research topics that are likely to deliver large environmental benefits; (2) design their research in a way that will increase its relevance, usefulness and potential impact on policy and, ultimately, the environment; and (3) make the case for funding particular research proposals. It could assist research agencies or research funders to: prioritize proposed research; make a case for increased funding for environmental research; and identify obstacles to the translation of research into environmental impacts, allowing attention to be focused on addressing these bottlenecks. 


\section{Key-words}

Applied research; Economics; Research evaluation; Research impact; Research prioritization; Environmental research

\section{Introduction}

Little is known about the returns to investments in environmental research.

Governments are requiring greater accountability, and some research funders are requiring information about research benefits to be provided in research proposals, but a coherent framework for evaluating the benefits resulting from environmental research is lacking.

Literature on the economics of research provides detailed guidance on how to estimate the benefits generated by research, and shows that typical rates of return on research investments in some fields are high (e.g., Alston et al., 2000; Productivity Commission, 2007; Hurley et al., 2014). However, existing methods are best developed for research that leads to reduced cost and thereby increased profit for commercial firms, or benefits to buyers from improved products or lower purchase prices (e.g., Alston et al., 2010; Hall and Rosenberg, 2010), or both. Research that is intended to provide "non-market" benefits-through the provision of environmental goods that are not fully priced in market transactions - is more difficult to evaluate, particularly if the target audience is policymakers (e.g., see Pardey and Smith, 2004). Few publications on the evaluation or prioritization of environmental research (e.g., Guidotti 1995; Wu and Hobbs, 2002; Spilki and Tundisi, 2010; Bell et al., 2011; Sutherland et al., 2011) make use of the extensive literature on the economics of research (Ferraro and Pattanayak, 2006).

The main objective in this paper is to identify and discuss principles, concepts, and methodological approaches for estimating benefits from environmental research, 
with a particular focus on policy-oriented research. In doing so, we use theory and evidence from existing literature, particularly in agricultural economics; we describe conceptual models of the mechanisms through which benefits arise from policyoriented environmental research; and we discuss the range of information required to estimate the benefits, and how that information can be combined to provide meaningful estimates of the benefits.

\section{Challenges in valuing benefits from environmental research}

That environmental research can generate benefits through improving policy seems obvious. Major environmental agencies around the world employ researchers, fund external researchers, and emphasize the importance of considering research results in policy. Examples of environmental issues where research appears to have played a role in prompting new policy or shaping changes in existing policy include global climate change (Manabe and Wetherald 1967), ozone pollution (Farman et al., 1985), management of renewable natural resource stocks such as fisheries (Smith et al., 2008), water pollution (Doole and Romera, 2015), soil conservation (Mitchell et al., 2016) and conservation of marine biodiversity (Possingham et al., 2009). However, quantitatively estimating the benefits that have resulted from the research that influenced these policies remains difficult, even when evaluating completed research.

To estimate the benefits from any type of research, a key challenge is the "attribution" problem: the difficulty of determining the contribution of particular research investments to a real-world outcome. Part of the difficulty arises because we have to estimate benefits from research as the difference between two scenarios: outcomes that occur with the research versus outcomes without the 
research (the "counterfactual" - Ferraro, 2009; McConnachie et al., 2016). Even if the research has already been undertaken and the results are known and in use, at least one of these scenarios - the second - is not observable. We have to estimate what would have been different if the research had not been undertaken. If the evaluation is of research that is yet to be conducted (e.g., to assist with setting research priorities), then even the results of the with-research scenario have to be predicted, adding further to the attribution problem. The challenge includes predicting what the research will yield, in terms of knowledge about the world, as well as how that new knowledge might be used in policy, and what the consequences of that use might be, allowing for the behavioral responses of diverse individuals.

Defining these scenarios (with research and without research) is made more difficult because research time lags are long and uncertain, and many changes occur in tandem. Typically, applied research takes years, perhaps decades, before it yields useful results that can be adopted. The adoption process itself then takes time as managers learn about the innovation and how to make it work best in their specific contexts. The effects of that adoption may persist for many years. For example, Alston et al. (2010) found that aggregate U.S. public agricultural research and extension had little effect on farm productivity within the first 10 years, and reached its maximum impact with a lag of 24 years, with residual impacts detectable beyond 40 years. Notably, these long time lags are predominantly for research that generates private benefits for the adopters. For environmental research, the lags may be even longer because the intended research users may lack the incentive to adopt, or face political barriers to adoption.

Whether evaluating research after its effects have fully unfolded, or anticipating future effects from research that may not have been done yet, it is necessary to make estimates of various parameters (see, e.g., Alston et al., 1995): (1) the costs 
attributable to the particular research investment (and to the associated adoption process if additional resources are required for that); (2) the time path and extent of adoption and use of the research results; (3) the magnitudes of the impacts on outcomes of interest (e.g., environmental conditions, costs) with adoption of the research results compared with a well-defined counterfactual without-research scenario; (4) the values associated with the changed environmental conditions attributable to the research, and (5) the benefits or costs of any side-effects of the changes resulting from the research investment.

In the case of policy-oriented environmental research, these challenges are exacerbated for at least two reasons. First, the benefits typically cannot be observed in market transactions. Second, the "adopter" of the research results is a policymaker or policy administrator rather than a commercial firm, so we usually cannot observe "adoption" as such. We may observe a policy change but we typically do not know whether we can ascribe it to a particular cause. In short, in addition to the general challenges in research evaluation, evaluating policy-oriented environmental research is especially problematic because of difficulties in ascribing a particular policy change to a particular research investment, estimating the consequential changes in environmental outcomes, and assigning a monetary value to them.

If the aim is to estimate the benefits that will arise from research that has not yet been conducted (ex ante research evaluations - as opposed to ex post evaluations conducted after the research has been completed), the difficulties are further increased. Importantly, research is an inherently risky business whose results cannot be known in advance. Many research projects will not yield information that is pertinent for policy decisions. We may know little about the time it takes to generate research results or the time it takes for those results to influence policy decisions and to see those decisions implemented. Looking forward 20 years or more, we have 
considerable uncertainty about the economic, environmental, social and political context in which policy changes will take effect. This uncertainty extends to the potential consequences of a policy change (presuming it does happen), the size of any adverse or favorable side-effects, and the counterfactual against which it should be compared.

\section{The role of research-based knowledge in the policy process}

We envision a policy process in which research plays a role by generating information that can change public or policymaker perceptions about the alternative policies and consequently can influence the policy choice. Our focus is on research that changes perceptions leading to altered policy decisions.

Suppose that various policy options are available for managing an environmental issue. The options may differ in their budgetary implications, policy mechanisms, spatial targeting, or approaches to policy implementation, as well as their effectiveness in managing the issue. Information obtained from research about their attributes influences which of the policy options is perceived to be superior. The comparison of the performance of the policies is based on perceptions and involves uncertainty, although probably less uncertainty than there would be without the research.

In the absence of research, a particular policy option would be chosen by policy makers. If the research project is conducted and yields policy-relevant information, it may lead policy makers to choose a different policy option. If the policy choice does not change, the research generates no benefits via this route, although it may do so in other ways. For example the new, research-based information may influence how people act in the presence of a given policy (e.g., the extent to which they comply 
with the policy), which could change the environmental outcomes even without changing the policy.

There are various possible mechanisms through which research could lead to a policy change. Most obviously, it could directly influence the perceptions of policymakers about the need for a policy, or the relative merits of the policy alternatives. It could generate technologies that make a policy more feasible or less costly, causing policy makers to switch from opposition to support for that policy. Alternatively, it could motivate people to advocate for policy change, thereby influencing policy decisions.

If the policy choice does change as a result of the research, the environmental benefits equal the community's value of the difference between environmental outcomes under the without-research policy, and the outcomes under the withresearch policy. This framework is essentially a Bayesian-style value-of-information analysis, long-established in economics and recently growing popular in applied ecology (e.g., Maxwell et al., 2015).

This description of the conceptual framework is silent about how research influences perceptions about the policies, how policy choice leads to particular environmental benefits, and the role of uncertainty. Every part of this system is characterized by significant uncertainty on the part of the policy analyst and the decision-maker, in part because we cannot observe at least one of the scenarios (with or without the research), and because the policy process is often complex and contested. Therefore the environmental values and research benefits are best described by probability distributions, representing the probabilities of different potential outcomes.

A key point highlighted by the framework is that all research evaluations entail comparing scenarios with and without the research in question. In an ex post assessment of completed research, one of those scenarios exists and can be observed-in terms of both the research investment and (perhaps) the policy 
decision-and the other is a hypothetical counterfactual alternative. In an ex ante assessment of proposed research, both scenarios are hypothetical. Whether the evaluation is ex post or ex ante, the main conceptual and measurement issues lie in predicting the different outcomes associated with alternative scenarios, ascribing a value to the differences, and assessing the share of that value attributable to research.

\section{The chain from research to environmental changes}

The links between environmental research and a policy decision are complex. We identify four stages in the process that may be thought of as forming a chain: research, policy decision, behavior and environmental conditions (Figure 1). The influence of research needs to be traced through each link in the chain. The existence of multiple stages (and potentially feedbacks between them) means that benefits are not just difficult to estimate, but can be difficult to achieve. The process can fail at any of the stages, resulting in failure of the research to deliver benefits. Here we discuss each of the stages, and outline the information required at each stage to estimate the benefits from research. For simplicity, Figure 1 portrays outcomes at each stage as binary; in reality each is a continuum. 


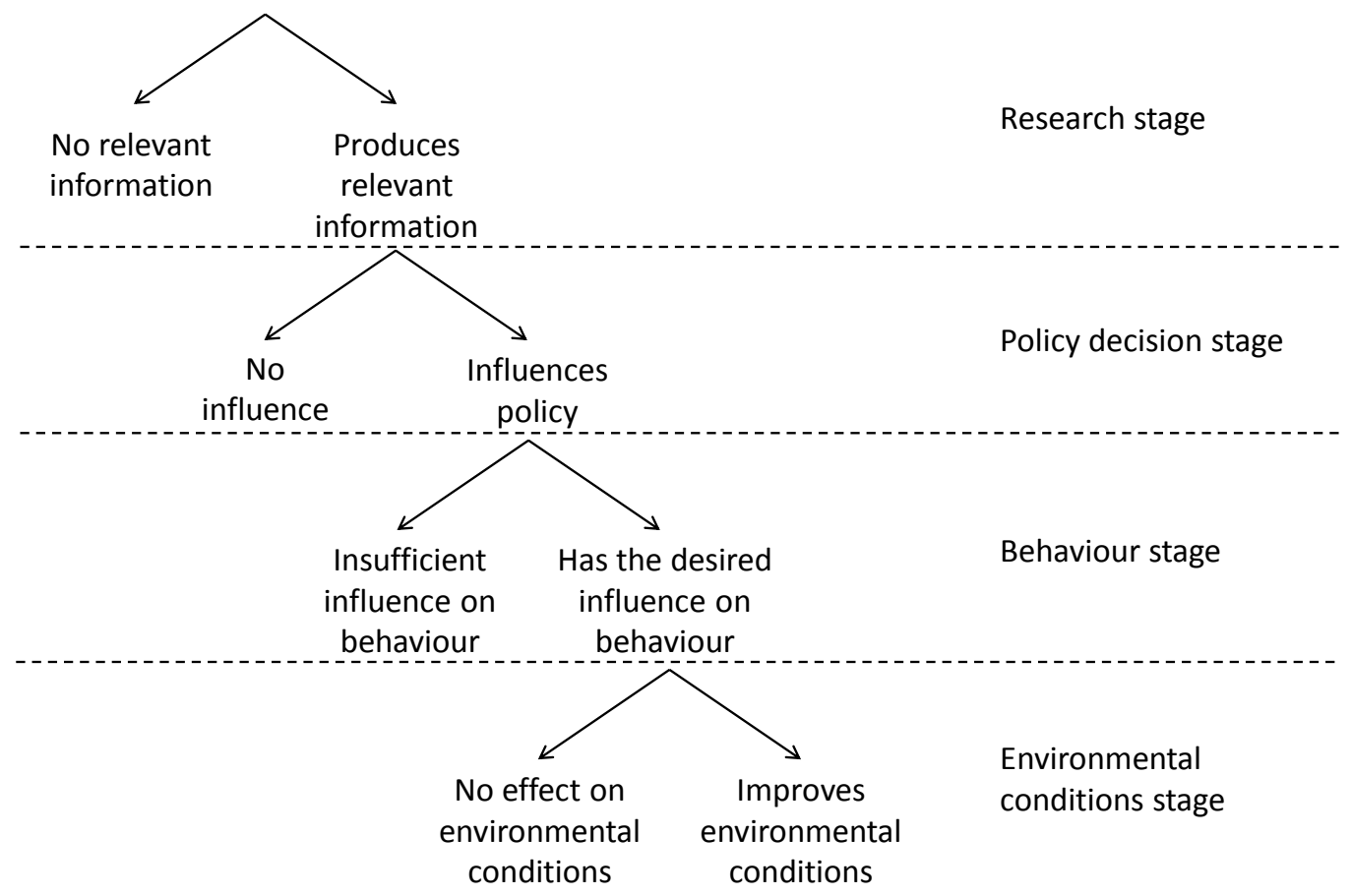

Figure 1. The chain from research to environmental changes.

\section{Research stage}

If the evaluation is being conducted after the research stage has been completed, an initial task is to identify the extent to which the research has generated relevant new information that has the potential to change policy decisions or their consequences. If the research has yet to be completed, the task of identifying the information outputs from the research has additional elements. Firstly, the information to be generated cannot be known, only anticipated. In principle, guided by Bayesian decision theory for calculating the value of sample information (Anderson et al., 1977; Canessa et al., 2015), we could anticipate a range of possible research results and assign to them subjective probabilities of the research generating each possible result. 
A number of factors should be considered when predicting or estimating the production of relevant information from the research. What policy-relevant information has arisen or is likely to arise from the research? In the case of ex ante assessments, what is the likelihood of the research generating the information anticipated by the researchers, considering researcher track record, researcher motivations, institutional support, available resources, and the anticipated difficulty of the research?

We would need to estimate the time lag until delivery of useful information. Shorter time lags in both the research and adoption phases are potentially beneficial for three reasons: (1) further environmental degradation is prevented; (2) benefits are generated over a longer time period; and ( 3 ) benefits are generated sooner (Pannell and Schilizzi, 2006).

The latter point is important because of the impact of time on benefits and costs. Economists use discounting to allow valid comparisons between benefits and costs that occur at different times (Gollier, 2013). Among several accepted rationales for discounting, the following two are most important: (1) resources invested in a project have an opportunity cost - they could have been invested in something else (e.g. a bank deposit or health services) to generate alternative benefits; (2) many people exhibit "pure time preference," meaning a preference for benefits sooner rather than later (irrespective of the opportunity cost issue). A consequence of discounting is that time lags in the generation of benefits from research result in those benefits being reduced in present-value terms, particularly for longer time lags. For example, assuming a $5 \%$ discount rate, a benefit realized in 30 years is worth about one-fifth of the value of the same benefit realized today. 
Having identified the new information arising from the research (or the probability distribution of potential new information in the case of future research), the next step is to identify or predict the extent and timing of policy change. Two aspects are relevant: change in stated policy (which might itself prompt some behavior change), and effective implementation of the new policy. It is necessary to identify future policy for both the with-research and without-research scenarios.

The time lag between the completion of the research and the occurrence of the policy change affects benefits in the same ways as described earlier for the research lag. In some cases, the policy-change lag is brief. For example, research contributed substantially to the design of a system of no-take areas in the Great Barrier Reef Marine Park, with the new system being implemented within a few years (Fernandes et al., 2005). In contrast, the first study on the causes of salinization of non-irrigated land in Western Australia was published in 1924 (Wood 1924). Over subsequent decades, a great deal of additional research was done on salinity, its impacts and its management, but it was not until 1996 that government established and resourced a cohesive policy (Beresford et al., 2001). The duration of the policy change prompted by the research will also affect the benefits of the research. For example, Australia's carbon tax, whose introduction in 2012 was attributable to the global research effort on climate change (IPCC, 2014), lasted only two years before being repealed following a change of government.

Information is needed about the extent to which an observed or predicted policy change can be attributed to particular research. It can be difficult to determine this when other research results vie for attention, or when policy decisions are influenced by factors other than research-based information. The environmental policy process is complex and hard to predict, and this affects the influence that 
research can have on policy decisions. Beyond the information provided by researchers, policymakers will probably "consider additional factors, such as legal mandates, societal desires, economic benefits and costs, rights, distributional equity and procedural fairness" (Pannell and Roberts, 2009 p.1089) as well as political strategy.

At the point in time when a policy change is being made, "policy generally moves faster than science, and the capacity of science to provide information may require more time than policymakers are willing to accept, especially for politically hot issues" (Clark et al., 1998, p. 9). On the other hand, in between major episodic policy changes there may be gaps of years or decades, and policy may lag behind the release of research results. Moreover, the research-based (scientific) knowledge that is available to policymakers today is derived from basic and applied research undertaken over many past years or decades, such that, of necessity, policy lags behind relevant research effort (Alston et al., 1995, 2010).

Policymakers often rely primarily on locally based experts who they know and trust (e.g., Feldman et al., 2001), and researchers who are not in this familiar group may find it difficult to have access and influence. Policymakers may be suspicious of the motives of researchers, and treat them as a lobby group. This may be exacerbated by some researchers acting as policy advocates (Pielke, 2007). Communication by researchers may be poor because the material is too complex or uses too much jargon or mathematics, or is located only in research journals that policymakers do not read (Pannell, 2004). Finally, policymakers may lack the capacity to understand scientific advice, a problem that is sometimes worsened by rapid turnover of policy staff.

Policy is also often influenced by lobbyists and interest groups, who may dispute scientific findings that imply policy decisions that conflict with their interests ( 
Jasanoff, 1987). Where an environmental issue is politically contested, the contest may include conflicting scientific arguments and evidence being put forward by different groups of scientists (championed by competing interest groups). This reduces the probability of any particular set of research results having a decisive influence on policy.

There are various factors to consider when predicting potential policy change arising from research (e.g., Dunlap et al., 2001; Schlager and Blomquist 2008; Seymour et al., 2008; Mills et al., 2013) including: (1) the extent to which the objectives of the potential adopters (i.e., policymakers and those responsible for policy implementation) include environmental protection or enhancement; (2) the capacity of adopters to interpret research results and/or to implement policy changes; (3) likely public support for the changes; and (4) the complexity and cost of policy changes suggested by the research - simpler or cheaper policies are more likely to be implemented. Beyond policy change, the benefits actually delivered depend on the likelihood that the new policy will actually be implemented.

Finally, in estimating the net benefits from research that influences policy, it is necessary to account for the transaction costs of changing policy (McCann et al., 2005). These include administrative costs, legal costs, and the costs of delivering public programs. These costs must be estimated with and without the research, with the difference being attributable to the research.

\section{Behavior stage}

Assuming that the research does lead to a policy change, in many cases the benefits will depend on the behavior of people involved in managing the relevant environmental assets, or managing other resources that have impacts on the environmental assets. These people may or may not respond to the policy in the intended ways. A great deal of research has investigated the determinants of 
behavior change, especially by landholders (e.g., Feder and Umali 1993; Pannell et al., 2006; Knowler and Bradshaw, 2007). This research highlights the complex nature of behavior change, with numerous variables coming into play in different cases. Again, predictions of behavior are needed with and without the research.

A related issue is the enforcement of policies that place obligations on people to take actions that benefit the environment or refrain from actions that harm it. If these policies require behaviors that people would not otherwise choose, then a commitment to enforcement can be critical.

A time lag is likely between policy implementation (or sometimes policy announcement) and behavior change, and should be factored into the evaluation of benefits. Evidence about time lags in adoption of new practices in agriculture shows considerable variation. Practices that are simple to adopt and highly profitable (such as Roundup Ready crops) are often adopted rapidly - in some cases most growers will adopt within a few years (e.g., Khan, 2015). Other practices that are more complex or less profitable or have other disadvantages (e.g., requiring local adaptation) may take much longer, potentially several decades (Alston et al., 1995, 2010). Where potential adopters are concerned about environmental outcomes, they will be more likely to adopt a practice when the benefits are readily observable and tangible to adopters (McCann et al., 2015).

The attribution problem recurs here in a different form: observed changes in behavior may or may not be attributable to a policy change. Behaviors change regularly in response to non-policy factors, such as price changes, new technologies (not generated by the research being evaluated) or new information. It can therefore be difficult to discern the effects of policy from the mix of influences.

Factors to consider when predicting behavioral responses to policy include: (1) the values, objectives and motivations of the particular people that the policy is 
intended to influence; (2) the characteristics of the specific new practices that the people are meant to adopt; (3) the favorability or unfavorability of the new practices, from the perspective of those people, with and without the policy; and (4) costs associated with the behavior change, including costs to government of promotion or enforcement, and costs imposed on private individuals as a result of enforcing a regulatory policy (Ban et al., 2013; Kuehne et al., 2017).

Behavior change also depends on the policy mechanisms used. Mechanisms based on persuasion or provision of information depend on the new behaviors or practices being sufficiently attractive to informed people that they are adopted voluntarily (Pannell et al., 2006). Mechanisms involving incentive payments or subsidies can prompt adoption of practices that would not otherwise have been accepted voluntarily, their effectiveness depending on the level of payments and on how unattractive (e.g., costly) the practices are. A regulatory mechanism (e.g. a ban on clearing vegetation) may or may not be complied with, depending on the cost of compliance, the likelihood of non-compliance being detected and the violator being fined, the expected magnitude of a fine, perceived fairness of the regulations, and societal acceptance of violations (e.g., Boakye, 2018).

\section{Environmental-conditions stage}

The changes in behavior induced by the policy change are intended to result in improvements in the condition or security of the relevant environmental assets. Even if the changes in policy and behavior were known with certainty, determining the nature and extent of physical changes in the environment can be challenging. For some issues, bio-physical models are available to assist with this task. For example, Beverly et al. (2011) show predicted changes in the extent of land salinization in south-eastern Australia as a result of changes in land management. However, cases with such strong evidence are relatively rare, particularly for issues related to 
biodiversity, threatened species, and vegetation. Often, little or no research results are available on the relationship between management and environmental outcomes, so the best available information is that derived from expert judgments (Yamada et al., 2003; Czembor and Vesk, 2009). In such cases, uncertainty about the relationships is unavoidably great.

It may be necessary to estimate a time lag between action and consequence. For example, the mechanism by which environmental benefits are generated may be the planting of trees to contribute to the restoration of habitat. The full environmental benefits from this strategy will not be realized until after the trees have matured, which, depending on the environment and the tree species, may take decades to centuries (Vesk et al., 2008). Similarly, in seven of the eight cases studied by Beverly et al. (2011), the estimated response time of groundwater (and therefore salinity) following a management change was between 40 and 94 years. Such time lags contribute to the overall lag between research and benefits, reducing the benefits in present-value terms.

Figure 2 illustrates the above four stages, with two scenarios representing what may happen to environmental conditions with research. In scenario (a), research-induced policy change results in a slowing in the decline of an environmental asset, but fails to halt the decline in its condition. For example, conservation policies have helped curb deforestation rates in the Brazilian Amazon, though rainforest continues to be lost (Assunção et al., 2015). Scenario (b) shows the outcome for research leading to a policy change that restores the environment to pristine or near-pristine conditions. This might apply to the original research into depletion of the ozone layer (UNEP, 2016). Both scenarios depict time lags owing to the research itself, policy decision making, policy implementation, behavior change and physical environmental change, reinforcing the earlier observation that the combined lags can be long. Of 
course there are many other possible patterns for environmental conditions, both in the with- and without-research scenarios.

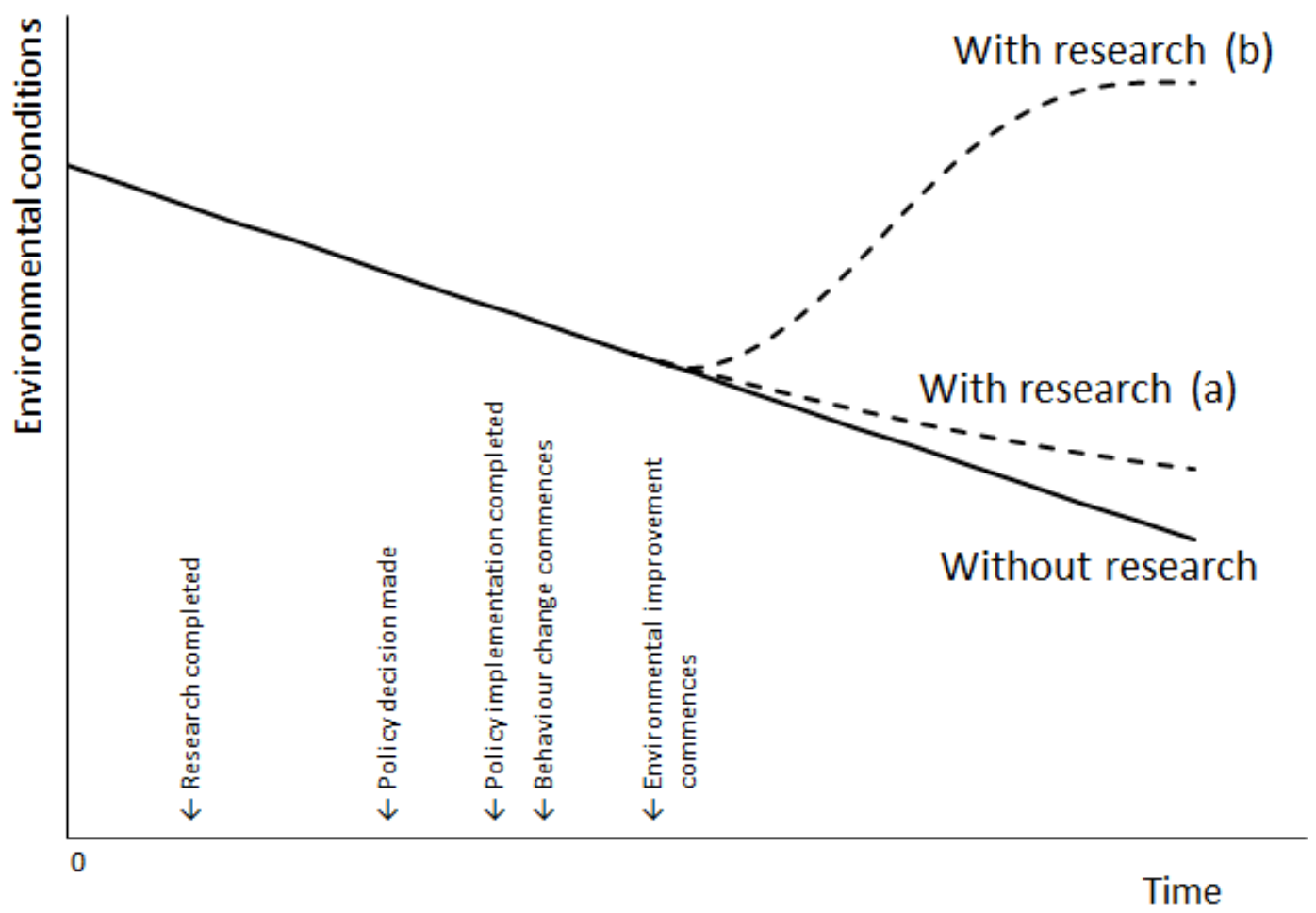

Figure 2. Hypothetical with-research and without-research scenarios showing two types of with-research scenarios, (a) and (b), and the various time lags prior to commencement of environmental improvement. In both cases, research commences at time zero.

\section{Valuation of benefits from the improved environmental conditions}

The analysis outlined in the previous section provides an assessment of the likely extent of change in environmental conditions or the quantity of an environmental 
good that will result from the research in question, potentially expressed probabilistically. The next step is to convert those changes into quantitative measures of benefit to the community.

The benefits derived from particular goods and services (including environmental goods and services) are context-sensitive. Relevant contexts for environmental research include: (1) the number of people who utilize or care about the environmental asset; (2) the nature and intensity of environmental appreciation; and (3) the availability of similar environmental assets that might serve as substitutes. To illustrate the latter point, conservation of 100 individuals of a highly-threatened species would likely be seen as more beneficial than conservation of 100 individuals of a widely-abundant species. This intuition of a negative relationship between abundance and marginal benefits (the change in benefit from a small, or marginal, change in quantity) is strongly supported by empirical evidence (e.g., Bateman et al., 2005).

Most evaluation of research relates to market goods, for which valuation is relatively tractable, involving application of the standard economic framework based on market prices for the good and market supply and demand curves. In the case of environmental research, however, some of the important goods are not traded in markets, and so require different estimation methods. Nevertheless, standard economic frameworks for estimating values based on supply and demand models are applicable to environmental public goods, at least conceptually. Our framework excludes benefits related to utility from the gaining of knowledge per se (e.g. please from knowledge itself). We do not imply that such knowledge lacks value - merely that our framework is not suitable for estimating its value.

The market demand curve for a traditional economic good provides the relationship between the quantity of a good consumed and its marginal benefit (MB). For an 
environmental good that is not traded in a market, we cannot directly observe a demand curve but we may be able to estimate the equivalent relationship between quantity available and marginal benefit, aggregating the benefits of all types across the whole community. A negative relationship between marginal benefit and abundance means that environmental "demand" curves slope down (Figure 3).

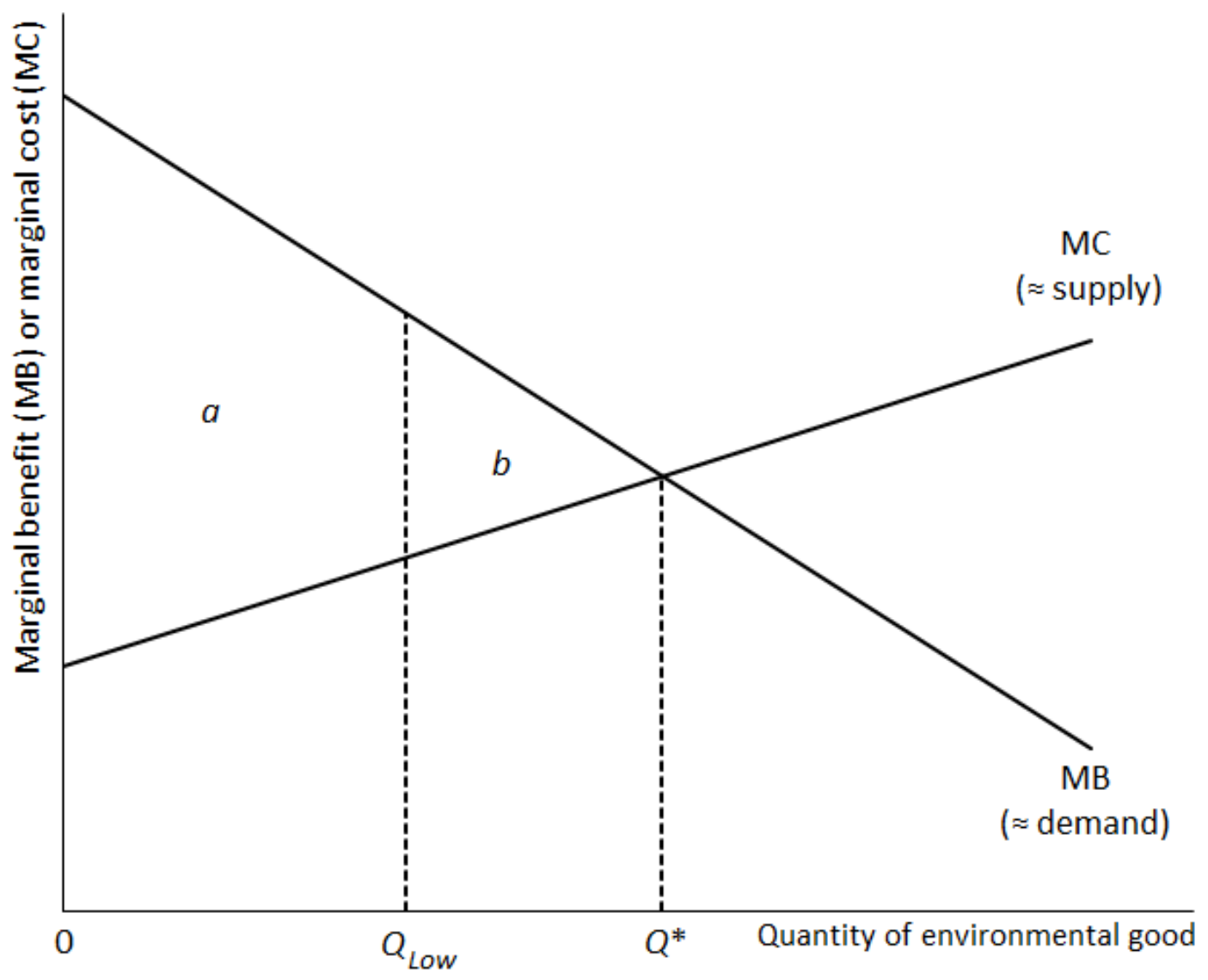

Figure 3. The "market" for an environmental good. The net benefit from providing quantity $Q_{\text {Low }}$ of the environmental good is area $a$ : the difference between the areas under marginal benefit and marginal cost. $Q^{*}$ is the quantity that maximizes the net benefit. Area $b$ is the gain in net benefits if quantity is increased from $Q_{\text {Low }}$ to $Q^{*}$. 
There is also the environmental equivalent of a market supply curve. It is the relationship between the quantity of the environmental good and the marginal cost (MC) of providing that quantity, incorporating all types of costs borne by all players, including governments. Environmental "supply" curves almost always slope up because it is increasingly expensive to incrementally increase the availability of an environmental good (e.g., Roberts et al., 2012; Hajkowicz et al., 2008) (Figure 3).

Assuming we know the marginal benefits and marginal costs of providing different quantities of an environmental good, we can use this information to measure the aggregate net benefits to society for any quantity of the good. Figure 3 , which combines the two curves onto one graph, looks like the standard model of supply and demand in a market, although there is no market in this case.

Suppose the existing quantity of the environmental good is $Q_{\text {Low. }}$ For reasons explained in any microeconomics text (e.g., Nicholson and Snyder, 2011), a measure of the aggregate benefits from experiencing $Q_{\text {Low }}$ units of the environmental good is the area below the MB curve up to the quantity $Q_{\text {Low. }}$ Similarly, the cost to society of supplying $Q_{\text {Low }}$ units of the good is the area below the MC curve up to the quantity $Q_{\text {Low. }}$ The benefits are experienced by whoever cares about this public good, while the costs may be borne by government-effectively by "taxpayers", who bear a share of the costs regardless of whether they personally benefit from the environmental good-or by businesses or individuals. Subtracting costs from benefits, the net benefits from $Q_{\text {Low }}$ units of the environmental good equal the area a.

Environmental research can yield benefits in the context of this model through three mechanisms. Firstly, research can yield information that equips the government to better determine the optimal quantity of the environmental good that should be provided. For instance, in Figure 3, research that allows the government to realize 
that quantity $Q^{*}$ is superior to $Q_{L o w}$, and consequently to take action to increase the provision of the environmental good to $Q^{*}$, would generate additional net benefits. The net benefits from the increase in $Q$ would be equal to area $b$ (counting just the benefits to demanders and the costs to suppliers of the good, not counting the costs of the research or the process of changing policy to bring about that increase in $Q$ ). The net benefits from better identifying $Q^{*}$ depend on the shapes of the MB and $M C$ curves, on the quantity that would be supplied without the research (i.e., $Q_{\text {Low }}$ in the above example), and on the ability (and willingness) of the government to raise that quantity to match $Q^{*}$.

A second mechanism entails research-induced reductions in the cost of providing the environmental good. Research can yield information that enables the environmental good to be provided at lower cost, or for more of the good to be provided at a given cost. For example, Doole et al. (2013) present a model that identifies least-cost combinations of practices to provide a given reduction in nutrient and sediment pollution in an Australian waterway. Polasky et al. (2001) modeled the optimal location of biological reserves to maximize environmental benefits for a given budget in Oregon.

As shown in Figure 4, this type of cost-reducing research leads to a shift in the MC function from $\mathrm{MC}_{0}$ to $\mathrm{MC}_{1}$. This implies an increase in the optimal quantity of the environmental public good from $Q_{0}{ }^{*}$ to $Q_{1}{ }^{*}$. Because the environmental good is now cheaper to provide, it is optimal to have more of it. The net benefits from the reduction in marginal costs in this case are measured as the area $g+h$ (assuming that the government does adopt the research result and, as a result, acts to increase the quantity of the environmental good provided from $Q_{0}{ }^{*}$ to $Q_{1}{ }^{*}$ ).

An extreme version of this second mechanism is where, in the absence of research, we don't know how to provide the environmental good at all (e.g. research to 
develop methods for captive breeding of a critically endangered species) effectively its cost is infinite. Research that provides information on how to provide the good can be interpreted as reducing its marginal cost of provision, and thus increasing its optimal quantity supplied from zero to a positive quantity.

A third mechanism by which research may generate benefits is through provision of information that allows better decision-making about which environmental goods to invest in. Commonly, the total funding available in government programs is not sufficient to resource all beneficial environmental projects. Research that allowed us to estimate the marginal benefits and marginal costs of providing different environmental outcomes could be used to improve estimates of the benefits for each available project, which would help us to better prioritize our overall portfolio of environmental investments (e.g., Gibson et al., 2017). 


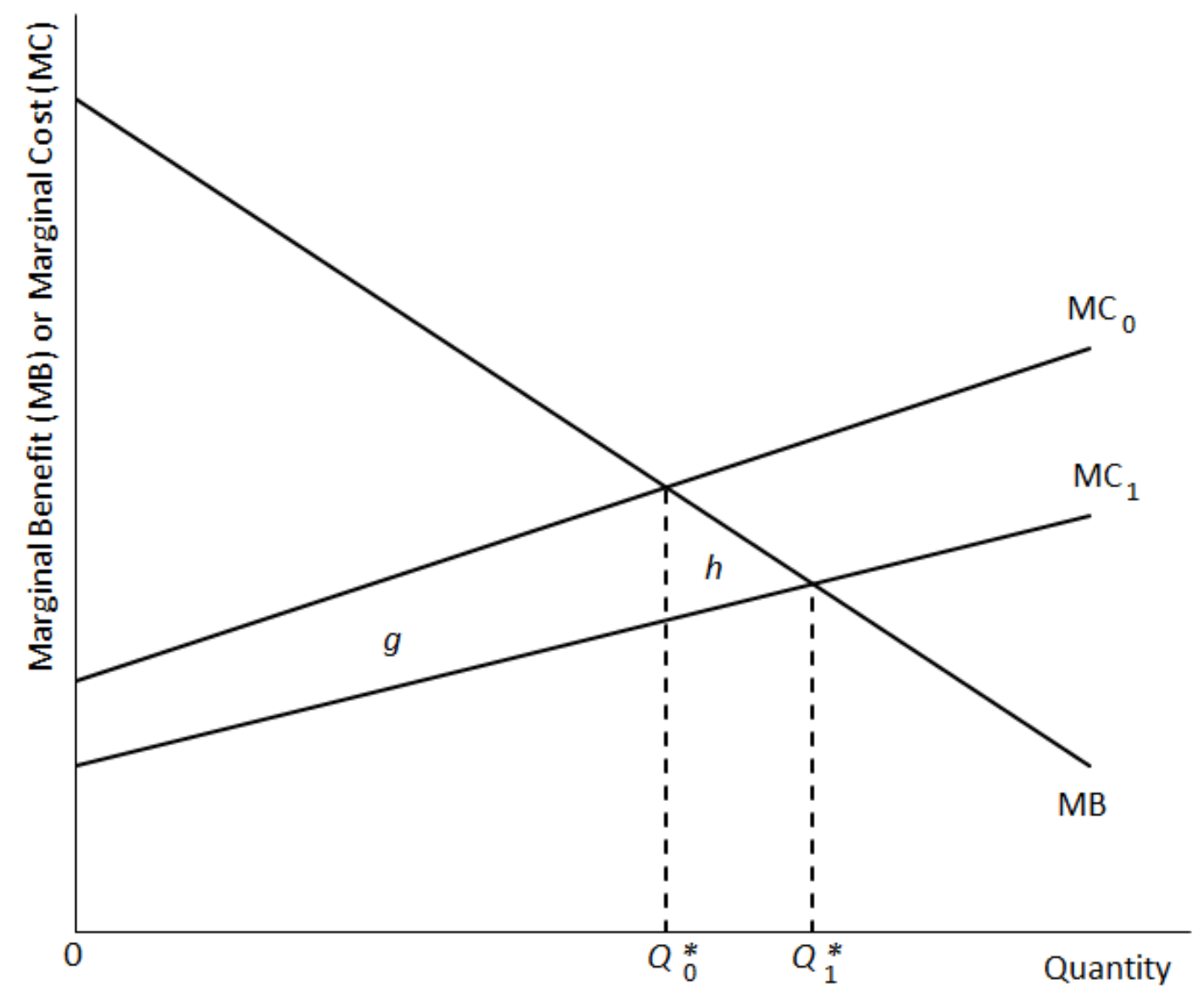

Figure 4. A research-induced decrease in the marginal cost of providing an environmental good potentially generates benefits equal to the area $g+h$. $\mathrm{MC}_{0}$ is the marginal cost of providing the environmental good without the research, $M C_{1}$ is the marginal cost with the research, area $g$ equals the net benefits from the research if quantity remains at $Q_{0} *$ and area $h$ equals the additional net benefits if quantity is adjusted to $Q_{1}{ }^{*}$ as a result of the research-induced cost reduction.

Although the framework outlined above has been widely used to estimate the benefits from research in various sectors, its application to environmental research is hampered by the difficulty of observing the marginal cost and marginal benefit functions for environmental goods. Economists have developed a range of methods for estimating non-market values as dollar values, including choice experiments 
(Adamowicz et al., 2014), contingent valuation (Alberini and Kahn, 2006), hedonic pricing (Baranzini et al., 2008) and the travel cost method (Willis and Garrod 1991). Each of these methods has different strengths and weaknesses (Bennett, 2011), and some are limited to estimating particular types of non-market benefits. In the absence of a market, estimating marginal cost requires detailed analysis of the costs associate with providing different levels of the good.

\section{Conclusion}

Estimation of the benefits of policy-oriented environmental research requires judgements about a range of variables, including: (1) the new information generated; (2) the likely extent of policy change resulting from the new information; (3) the likely extent of environmentally beneficial behavior change resulting from the policy change; (4) the likely environmental changes and other changes that will result from the predicted behavior change; (5) the value or importance of the anticipated environmental changes and other changes; and (6) the time lags involved in research, and the consequently induced policy change, behavior change, and environmental change. Realistic assessments of research benefits need to weigh up all of these factors, rather than focusing on one or a few factors. A research project focusing on an area of policy that is judged negatively on one factor (e.g., political feasibility) might still be judged to be a priority if the other factors are sufficiently positive.

Given the challenges of obtaining the required information, it may be possible to facilitate the process by conducting research designed to address key knowledge gaps. This might include, for example, research into: (1) the time lags that are typical for research, policy influence, behavior change and environmental change; (2) the probability of policy-relevant research actually influencing policy in different 
circumstances; (3) the typical extent of behavior change resulting from different types of policies; and (4) good case-study examples to demonstrate the process.

To increase the application of these principles, it would be beneficial to develop frameworks and tools that support their relatively simple application. Given the complexity of the task, simplified tools (that are consistent with the principles outlined here as far as possible) are likely to be more realistic for use by individual scientists and perhaps even agencies. However, we also hope to see an increase in comprehensive analyses, in order to provide the richest insights into the processes of environmental research generating environmental benefits that are valued by the community.

An increased effort to quantify the benefits and costs of policy-oriented environmental research could generate benefits in various ways. It could assist environmental scientists to: (1) select research topics that are likely to deliver high environmental benefits; (2) design their research in a way that will increase its relevance for making better-informed environmental policy; and (3) make the case for funding particular research proposals. It may also assist research agencies or research funders to: (1) prioritize proposed research; (2) make a case for increased funding for environmental research; and (3) identify bottlenecks in the process of research leading to environmental impacts, allowing attention to be focused on addressing these bottlenecks.

Several governments have introduced policies requiring researchers to demonstrate the relevance and impact of their research. It seems that there has so far been little recognition of the inherent difficulties (outlined in this paper) in estimating the benefits from policy-oriented environmental research. Even in evaluation studies undertaken after the research has been completed and the research findings are known, long time lags and the counterfactual question (including attribution) can 
make the task extremely challenging. Realistic expectations about what scientists can say about research benefits are needed.

\section{Authors' Contributions}

All authors contributed to the ideas, concepts and frameworks presented. SJ collected and analyzed existing literature. DP and JA led the writing of the manuscript. All authors contributed critically to the drafts and gave final approval for publication.

\section{Acknowledgements}

The authors are grateful to the ARC Centre of Excellence for Environmental Decisions (grant number CE1101014) for funding support.

\section{References}

Adamowicz, W.L., Glenk, K. and Meyerhoff, J. (2014). Choice modelling research in environmental and resource economics, In: Hess, S. and Daly, A. (eds.), Handbook of Choice Modelling, Edward Elgar, Cheltenham, UK and Northampton, MA, USA, pp. 661-674.

Alberini, A. and Kahn, J.R. (eds.) (2006). Handbook On Contingent Valuation, Edward Elgar, Cheltenham, UK and Northampton, MA, USA.

Alston, J.M., Andersen, M.A., James, J.S. and Pardey, P.G. (2010). Persistence Pays: U.S. Agricultural Productivity Growth and the Benefits from Public R\&D Spending, Springer, New York.

Alston, J.M., Chan-Kang, C., Marra, M.C., Pardey, P.G. and Wyatt, T.J. (2000). A Meta-Analysis of the Rates of Return to Agricultural R\&D: Ex Pede Herculem. IFPRI Research Report No. 113, International Food Policy Research Institute, Washington D.C.

Alston, J.M., Norton, G.W. and Pardey, P.G. (1995). Science Under Scarcity: Principles and Practice for Agricultural Research Evaluation and Priority Setting. Cornell University Press, Ithaca.

Anderson, J.R., Dillon, J.L. and Hardaker, J.B. (1977). Agricultural Decision Analysis, lowa State University Press, Ames.

Assunção, J., Gandour, C., and Rocha, R. (2015). Deforestation slowdown in the Brazilian Amazon: Prices or policies? Environment and Development Economics 20(6), 697-722. 
Ban, N.C., Mills, M., Tam, J., Hicks, C.C., Klain, S., Stoeckl, N., Bottrill, M.C., Levine, J., Pressey, R.L., Satterfield, T. and Chan, K.M. (2013). A social-ecological approach to conservation planning: embedding social considerations, Frontiers in Ecology and the Environment 11, 194-202.

Baranzini, A., Ramirez, J., Schaerer, C. and Thalmann, P. (eds.) (2008). Hedonic Methods in Housing Markets: Pricing Environmental Amenities and Segregation, Springer, Dordrecht.

Bateman, I.J., Cooper, P., Georgiou, S., Navrud, S., Poe, G.L., Ready, R.C., Riera, P., Ryan, M. and Vossler, C.A. (2005). Economic valuation of policies for managing acidity in remote mountain lakes: Examining validity through scope sensitivity testing, Aquatic Sciences 67, 274-291.

Bell, S., Shaw, B. and Boaz, A. (2011). Real-world approaches to assessing the impact of environmental research on policy, Research Evaluation 20(3), 227-237.

Bennett, J. (ed.) (2011). The International Handbook on Non-Market Environmental Valuation, Edward Elgar, Cheltenham, UK and Northampton, MA, USA.

Beresford, Q., Bekle, H., Phillips, H. and Mulcock, J. (2001). The Salinity Crisis: Landscapes, Communities and Politics, University of Western Australia Press, Nedlands.

Beverly, C., Roberts, A., Hocking, M., Pannell, D. and Dyson, P. (2011). Using linked surfacegroundwater catchment modelling to assess protection options for environmental assets threatened by dryland salinity in southern-eastern Australia, Journal of Hydrology 410, 13-30.

Boakye, J. (2018) Understanding motivations for violation of timber harvesting regulation: The case of chainsaw operators in Ghana, Forest Policy and Economics 87, 85-92.

Canessa, S., Guillera-Arroita, G., Lahoz-Monfort, J.J., Southwell, D.M., Armstrong, D.P., Chadès, I., Lacy, R.C. and Converse, S.J. (2015). When do we need more data? A primer on calculating the value of information for applied ecologists, Methods in Ecology and Evolution 6(10), 1219-1228.

Clark, R.N., Meidinger, E.E., Miller, G., Rayner, J., Layseca, M., Monreal, S., Fernandez, J., Shannon, M.A. (1998). Integrating science and policy in natural resource management: lessons and opportunities from North America. General Technical Report PNW-GTR-441. U.S. Department of Agriculture, Forest Service, Pacific Northwest Research Station, Portland, OR, 22 pp.

Czembor, C. A., and Vesk, P. A. (2009). Incorporating between-expert uncertainty into state-andtransition simulation models for forest restoration, Forest Ecology and Management 259(2), 165175.

Doole, G.J. and Romera, A.J. (2015). Trade-offs between profit, production, and environmental footprint on pasture-based dairy farms in the Waikato region of New Zealand, Agricultural Systems 141, 14-23.

Doole, G., Vigiak, O., Roberts, A.M. and Pannell, D.J. (2013). Cost-effective strategies to mitigate multiple pollutants in an agricultural catchment in North-Central Victoria, Australia, Australian Journal of Agricultural and Resource Economics 57(3), 441-460.

Dunlap, R.E., Xiao, C. and McCright, A.M. (2001). Politics and environment in America: partisan and ideological cleavages in public support for environmentalism, Environmental Politics 10(4), 23-48.

Farman, J.C., Gardiner, B.G. and Shanklin, J.D. (1985). Large losses of total ozone in Antarctica reveal seasonal $\mathrm{ClO}_{x} / \mathrm{NO}_{x}$ interaction, Nature 315, 207-210.

Feder, G. and Umali, D. (1993). The adoption of agricultural innovations: a review, Technological Forecasting and Social Change 43, 215-239. 
Feldman, P.H., Nadash, P., Gursen, M. (2001). Improving communication between researchers and policy makers in long-term care: or, researchers are from Mars; policy makers are from Venus, Gerontologist 41, 312-321.

Ferraro, P.J. (2009). Counterfactual thinking and impact evaluation in environmental policy, New Directions for Evaluation 122, 75-84.

Ferraro, P.J. and Pattanayak, S.K. (2006). Money for nothing? A call for empirical evaluation of biodiversity conservation investments, PLOS Biology 4(4), e105.

Gibson, F.L., Rogers, A.A., Smith, A.D.M., Roberts, A., Possingham, H., McCarthy, M. and Pannell, D.J., (2017). Factors influencing the use of decision support tools in the development and design of conservation policy, Environmental Science and Policy 70(1), 1-8.

Gollier, C. (2013). Pricing the Planet's Future: The Economics of Discounting in an Uncertain World, Princeton University Press, Princeton.

Guidotti, T.L. (1995). Managing environmental research in a government agency: priorities in chemical hazards, Environmental Research 68, 133-139.

Hajkowicz, S., Spencer, R., Higgins, A. and Marinoni, A. (2008). Evaluating water quality investments using cost utility analysis, Journal of Environmental Management 88, 1601-1610.

Hall, B.H. and Rosenberg, N. eds. (2010). Handbook of Economics of Technical Change, Elsevier, Amsterdam.

Hurley, T.M, Rao, X. and Pardey, P.G. (2014). Re-examining the reported rates of return to food and agricultural research and development, American Journal of Agricultural Economics 96(5), 1492 1504.

Intergovernmental Panel on Climate Change (IPCC) (2014). Climate Change 2014: Synthesis Report. Contribution of Working Groups I, II and III to the Fifth Assessment Report of the Intergovernmental Panel on Climate Change [Core Writing Team, R.K. Pachauri and L.A. Meyer (eds.)]. IPCC, Geneva, Switzerland, $151 \mathrm{pp}$.

Jasanoff, S.S. (1987). Contested boundaries in policy-relevant science, Social Studies of Science 17(2), $195-230$

Khan, M.F.R. (2015). Update on adoption of glyphosate-tolerant sugar beet in the United States, Outlooks on Pest Management 26(2), 61-65.

Knowler, D., and Bradshaw, B. (2007). Farmers' adoption of conservation agriculture: A review and synthesis of recent research, Food Policy 32: 25-48.

Kuehne, G., Llewellyn, R., Pannell, D.J., Wilkinson, R., Dolling, P., Ouzman, J. and Ewing, M. (2017). Predicting farmer uptake of new agricultural practices: a tool for research, extension and policy, Agricultural Systems 156, 115-125.

Manabe, S. and Wetherald, R.T. (1967). Thermal equilibrium of the atmosphere with a given distribution of relative humidity, Journal of the Atmospheric Sciences 24(3), 241-259.

Maxwell, S.L., Rhodes, J.R., Runge, M.C., Possingham, H.P., Ng, C.F., Mcdonald-Madden, E. (2015). How much is new information worth? Evaluating the financial benefit of resolving management uncertainty, Journal of Applied Ecology 52(1), 12-20.

McCann, L., Colby, B., Easter, K.W., Kasterine, A. and Kuperan, K.V. (2005). Transaction cost measurement for evaluating environmental policies, Ecological Economics 52, 527-542. 
McCann, L., Gedikoglu, H., Broz, B., Lory, J., and Massey, R. (2015). Effects of observability and complexity on farmers' adoption of environmental practices, Journal of Environmental Planning and Management 58(8), 1346-1362.

McConnachie, M.M., Van Wilgen, B.W., Ferraro, P.J., Forsyth, A.T., Richardson, D.M., Gaertner, M. and Cowling, R.M. (2016). Using counterfactuals to evaluate the cost-effectiveness of controlling biological invasions, Ecological Applications 26(2), 475-483.

Mills, M., Pressey, R.L., Ban, N.C., Foale, S., Aswani, S. and Knight, A.T. (2013). Understanding characteristics that define the feasibility of conservation actions in a common pool marine resource governance system, Conservation Letters 6, 418-429.

Mitchell, J.P., Carter, L.M., Reicosky, D.C., Shrestha, A., Pettygrove, G.S., Klonsky, K.M., Marcum, D.B., Chessman, D., Roy, R., Hogan, P., and Dunning, L. (2016). A history of tillage in California's Central Valley, Soil and Tillage Research 157, 52-64.

Nicholson, W. and Snyder, C.M. (2011). Microeconomic Theory: Basic Principles and Extensions, $11^{\text {th }}$ edition, Cengage Learning, Boston.

Pannell, D.J. (2004). Effectively communicating economics to policy makers, Australian Journal of Agricultural and Resource Economics 48(3), 535-555.

Pannell, D.J. and Roberts, A.M. (2009). Conducting and delivering integrated research to influence land-use policy: salinity policy in Australia, Environmental Science and Policy 12(8), 1088-1099.

Pannell, D.J. and Schilizzi, S. (eds) (2006). Economics and the Future: Time and Discounting in Private and Public Decision Making, Edward Elgar, Cheltenham, UK and Northampton, MA, USA.

Pannell, D.J., Marshall, G.R., Barr, N., Curtis, A., Vanclay, F. and Wilkinson, R. (2006). Understanding and promoting adoption of conservation practices by rural landholders. Australian Journal of Experimental Agriculture 46(11), 1407-1424.

Pardey, P.G. and Smith, V.H. eds. (2004). What's Economics Worth? Johns Hopkins University Press, Baltimore.

Pielke, R.A. (2007). The Honest Broker: Making Sense of Science in Policy and Politics. Cambridge University Press, New York.

Polasky, S., Camm, J.D. and Garber-Yonts, B. (2001). Selecting biological reserves cost-effectively: An application to terrestrial vertebrate conservation in Oregon, Land Economics 77(1), 68-78.

Possingham, H., Ward, T., Stewart, R., Segan, D. and Kircher, L. (2009). Systematic conservation planning: A network of marine sanctuaries for the Commonwealth's South-West Marine Region, Prepared for PEW Environment Group, Log No: 2006-000202.

Productivity Commission (2007). Public Support for Science and Innovation, Research Report, Productivity Commission, Canberra.

Roberts, A.M. Pannell, D.J. Doole, G. and Vigiak, O. (2012). Agricultural land management strategies to reduce phosphorus loads in the Gippsland Lakes, Australia, Agricultural Systems 106(1), 11-22.

Schlager, E. and Blomquist, W. (2008). Embracing Watershed Politics, University Press of Colorado, Boulder, CO, USA.

Seymour, E., Pannell, D.J., Roberts, A.M., Marsh, S. and Wilkinson, R. (2008). Decision making by catchment management organisations in Australia: current processes and capacity gaps, Australasian Journal of Environmental Management 15(4), 211-221. 
Smith, A.D.M., Smith, D.C., Tuck, G.N., Klaer, N., Punt, A.E., Knuckey, I., Prince, J., Morison, A., Kloser, R., Haddon, M., Wayte, S., Day, J., Fay, G., Pribac, F., Fuller, M., Taylor, B. and Little, L.R. (2008). Experience in implementing harvest strategies in Australia's south-eastern fisheries, Fisheries Research 94, 373-379.

Spilki, F.R. and Tundisi, J.G. (2010). Priority targets for environmental research in the Sinos River basin, Brazilian Journal of Biology 70(4, suppl.), 1245-1247.

Sutherland, W.J., Goulson, D., Potts, S.G. and Dicks, L.V. (2011). Quantifying the impact and relevance of scientific research, PLoS one 6(11), e27537.

United Nations Environment Program (UNEP). (2016). Handbook for the Montreal Protocol on Substances that Deplete the Ozone Layer, Tenth edition, United Nations Environment Program, Nairobi, Kenya, 749 pp.

Vesk, P. A., Nolan, R., Thomson, J. R., Dorrough, J. W., and Mac Nally, R. (2008). Time lags in provision of habitat resources through revegetation, Biological Conservation 141(1), 174-186.

Willis, K.G. and Garrod, G.D. (1991). An individual travel-cost method of evaluating forest recreation, Journal of Agricultural Economics 42(1), 33-42.

Wood, W.E. (1924). Increase of salt in soil and streams following the destruction of the native vegetation, Journal of the Royal Society of Western Australia 10, 35-47.

Wu, J. and Hobbs, R. (2002). Key issues and research priorities in landscape ecology: An idiosyncratic synthesis, Landscape Ecology 17, 355-365.

Yamada, K., Elith, J., McCarthy, M. and Zerger, A. (2003). Eliciting and integrating expert knowledge for wildlife habitat modelling. Ecological Modelling 165(2), 251-264. 